\title{
reviews
}

\section{How man has seen the world}

THE declared aim of this ambitious handbook* is "to bring together essential aspects of the very large, diverse and widely scattered literature on human perception." The present volumes are the first of 12; a third volume, Biology of Perceptual Systems, was published in 1973. Volumes 4-6 will cover the individual senses; and in the last six volumes it is planned to include areas such as speech and language, aesthetics, the perception of form, of space and of objects, and the perceptual aspects of thought.

Yet this is not a handbook. It is a very large collection of essays. There are many notable chapters by individual contributors, but the sum of the parts cannot fairly be represented as a true handbook. Cross-references within and between volumes are almost completely absent and there is much internal evidence to suggest that contributors have not read each other's chapters: thus, R. M. Boynton, who gives an account in Volume 1 of $\mathbf{J}$. $\mathbf{J}$. Gibson's theory of visual perception, cannot have been invited to read those passages in the same volume in which M. Wertheimer makes the elementary mistake of speaking of visual receptors firing impulses.

Indeed, there is grave doubt as to whether the editors themselves have read all the contributions. Very often the same ground is covered two or three times without comment or crossreference, so that the reader is left wondering whether he is missing some subtlety; there seem, for example, to be three introductions to epistemology, two introductions to psychophysics and two accounts of multidimensional scaling. The very sequence of chapters is sometimes bizarre : a chapter by J. R.

'Handbook of Perception. Vol. 1: Iistorical and Philosophical Roots of erception. Pp. xix +431 . $\$ 23.50$; 11.30. Vol. 2: Psychological Judgeent and Measurement. Pp. xix +556. 9.50; £14.15. Edited by Edward C. urterette and Morton P. Friedman. cademic: New York and London, 74.)

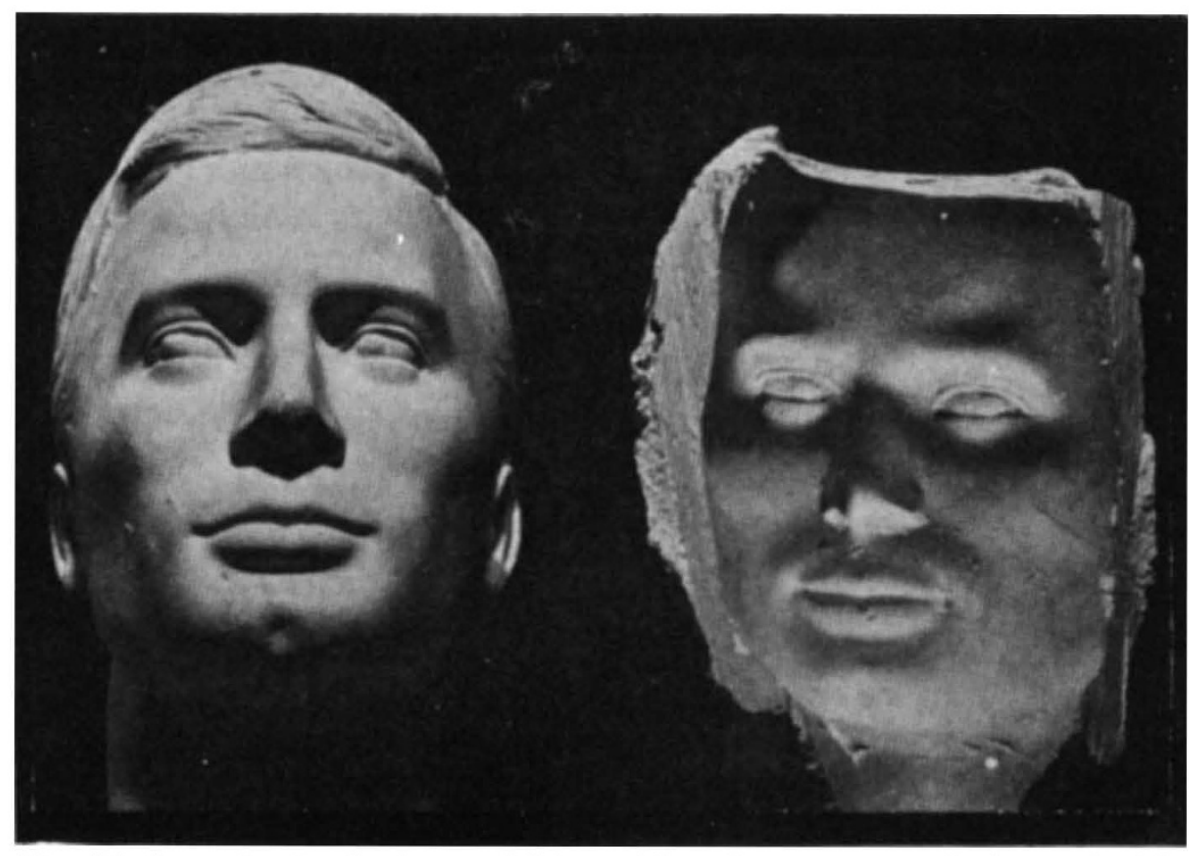

Though both are viewed under the same lighting and have the same texture, the face on the right does not appear as a mould of that on the left.

Royce on epistemological psychology appears, inexplicably, in the historical section of Volume 1, whereas, if it belonged anywhere in that volume, it would have been as a bridge between the philosophical and the psychological sections. Similarly, in Volume 2, a relatively technical paper by A. Sandusky on memory effects in psychophysics is separated from A. Parducci's paper on contextual effects and is instead inserted between a short and very readable introduction to psychophysics by $F$. Nowell Jones and a long and very readable introduction to psychophysics by E. Galanter. In short, in spite of the 2 editors and 17 members of the editorial board, almost the only evidence of an editorial hand is the use throughout of $c f$ where $v$ is properly required.

The editors must, however, enjoy some credit for their choice of contributors. Many of the individual chapters are of a very high standard, particularly Hochberg's excellent review of the history and present state of the Gestalt tradition; Berlyne's introduction to attention; Garner's introduction to attention; and the comprehensive account of multidimensional scaling by Carroll and Wish. Luce and Green combine to write a supplement to the 1966 book on signal detection theory by Green and Swets. R. L. Gregory, in a section of Volume 1 devoted to grand theories of perception, does what the editors have failed to do and contrasts different theoretical approaches, considering the capacity of each to accommodate a number of facts that he has carefully chosen to support his own view that "perceptions are hypotheses". Elsewhere in the same volume there is a critique of this class of theory by Metzger but, characteristically, there are no cross-references between his chapter and those by Gregory and Hochberg.

Although Volume 1 is entitled Historical and Philosophical Roots of Perception, the history of perceptual theory is covered very inadequately. The origins of the sensory sciences in physics and medicine are almost completely neglected, as is the history of the study of senses other than vision. Such history as is dealt with reads soundly, but it is often drawn from secondary sources and professional historians of science would judge it presentist and Whiggish. In recent years historians of science have notoriously drawn upon psychological illustrations of the hypothetical nature of perception and thus it is the more unhappily ironic that this opportunity has not been taken to introduce a more hermeneutic approach to the history of perceptual theory and to discuss theories of perception in the context of the way man has seen the world.

J. D. Mollon 